\title{
Paraphilic Interests: The Role of Psychosocial Factors in a Sample of Young Adults in Hong Kong
}

\author{
Heng Choon (Oliver) Chan ${ }^{1}$ D
}

Accepted: 30 December 2020 / Published online: 19 February 2021

(C) The Author(s) 2021, corrected publication 2021

\begin{abstract}
Background Little is known about the prevalence and nature of paraphilic interests in the Hong Kong young adult population. This study explores the psychosocial factors associated with paraphilic interests.

Methods Testing the propositions of several criminological theories (i.e., the theories of self-control, general strain, social learning, social control, and routine activity), the study recruited 1171 participants (18-40 years old), from September 2018 through April 2020, to examine both general and 14 subtypes of paraphilic interest (i.e., voyeurism, exhibitionism, scatologia, fetishism, transvestic fetishism, frotteurism, sadism, masochism, biastophilia, urophilia, scatophilia, hebephilia, pedophilia, and zoophilia).

Results The findings indicate that males reported significantly higher levels of general and 12 subtypes of paraphilic interest than females, while females had a higher level of transvestic fetishism than males. No mean difference is found between males and females in interest in masochism. Relative to females, males reported significantly higher levels of negative temperament, alcohol and drug use, and risky sexual behavior, whereas females had higher levels of self-control, social bonds, and perceived neighborhood disorganization than males. Multivariate analyses indicate that in general, high levels of negative temperament, alcohol and drug use, risky sexual behavior, and perceived neighborhood disorganization and low levels of self-control and social bonds were important factors associated with the participants' likelihood of having general and 14 subtypes of paraphilic interest.

Conclusions These findings provide support to the significant role of psychosocial factors in understanding different paraphilic interests in the Hong Kong young adult population.

Policy Implications This study has implications for practice, in the form of reducing, if not eliminating, the tendency to develop an interest in paraphilic behaviors. This may be more important when referring to paraphilic behaviors that are criminally oriented.
\end{abstract}

Keywords Paraphilic interest $\cdot$ Paraphilic behavior $\cdot$ Paraphilia $\cdot$ Psychosocial factor $\cdot$ Young adult

\section{Introduction}

Paraphilias can be broadly defined as conditions characterized by persistent unconventional sexual interests. Clinically, a paraphilia has been defined as an "intense and persistent sexual interest other than sexual interest in genital stimulation or preparatory fondling with phenotypically normal, physically mature, consenting human

Heng Choon (Oliver) Chan

oliverchan.ss@cityu.edu.hk

1 Teaching Laboratory for Forensics and Criminology, Department of Social and Behavioral Sciences, City University of Hong Kong, Kowloon, Hong Kong S.A.R. partners" (American Psychiatric Association, 2013). Paraphilic sexual interest is regarded as sexual arousal from an atypical sexual activity (e.g., exposing one's genitals to nonconsenting others) or target (e.g., prepubescent children) (Bouchard, Dawson, \& Lalumière, 2017). However, it should be stressed that having or acting on a paraphilic interest may not necessarily be pathological. Most people with paraphilic interests do not have a mental disorder, and paraphilia is only clinically diagnosed when the paraphilic interest is recurrent, persistent, necessary for sexual enjoyment, and results in significant distress or impairment of functioning. Nevertheless, some studies found a significant positive relationship between antisociality (e.g., antisocial personality disorder, conduct disorder) and paraphilic 
interests and behavior, particularly in the criminal population (DeLisi, Drury, Caropreso, Heinrichs, Tahja, \& Elbert, 2018; Lee, Hanson, Calkins, \& Jeglic, 2020). The Diagnostic and Statistical Manual of Mental Disorders, Fifth Edition (DSM-5) identifies eight paraphilias and their associated paraphilic disorders (i.e., voyeurism, exhibitionism, fetishism, transvestic fetishism, frotteurism, sexual sadism, sexual masochism, and pedophilia; APA, 2013), while the International Classification of Diseases, Tenth Revision (ICD-10) recognizes six disorders of sexual preference (i.e., voyeurism, exhibitionism, fetishism, fetishistic transvestism, sadomasochism, and pedophilia; World Health Organization, 2010). Other paraphilias are classified in DSM-5 in the residual diagnosis category of paraphilia (e.g., scatologia, biastophilia, urophilia, scatophilia, hebephilia, and zoophilia).

Given the flexibility of sexual norms across time and cultural practices, the DSM-5 has distinguished paraphilias from paraphilic disorders, with the former is regarded as atypical but not inherently pathological behaviors. Paraphilic disorders, in contrast, are regarded as the presence of deviant, maladaptive erotic urges, which may result in a significant threat to the psychological and physical well-being of the affected individuals and/or others. Indeed, the diagnosis of paraphilic disorders requires that (1) the patient experiences personal distress over persistent (at least 6 months) and troubling sexual fantasies, urges, or behaviors (and not simply from society's disapproval), and that (2) such behaviors cause distress, injury, or death of another individuals, or involve nonconsenting individuals or those who are unable to provide legal consent (American Psychiatric Association, 2013).

However, sexual fantasies should not be confused with sexual interests. Joyal and colleagues (2015) found in their nonclinical samples that self-reported sexual fantasies were regarded as the mere presence of a paraphilic sexual fantasy that may not essentially indicative of a paraphilic interest. In fact, many participants in their study who reported submissive or rape fantasies stated that they would never want to have such experiences. Furthermore, numerous studies of nonclinical samples have demonstrated that the interest in and practice of paraphilic behavior (e.g., nonoffending paraphilic interests) may merely use to enhance the overall sexual satisfaction with their partner (Joyal, 2014; Khar, 2008; Leitenberg \& Henning, 1995). A recent study by Mundy and Cioe (2019) found in their nonclinical sample that those who have a paraphilic interest and have disclosed to their partner have higher levels of sexual satisfaction than those who have not revealed their paraphilic interest to their partner of who do not have a stable partner. Hence, Critelli and Bivona (2008) argued that suggesting an individual of having sexual interests or fantasies related to an illegal and paraphilic act (e.g., biastophilia, pedophilia) is at a higher risk for criminality is inaccurate as it may not necessarily the case.

Culture and society are also found to have a significant impact on the recognition and acceptance of behavior as normal or deviance. Sexual practices, in general, are associated with the societal kinship structures and power gradients, which often follow prescribed and shared cultural scripts that promote or discourage different types of sexual interests and behavior (Reiss, 1986). Specifically, Bullough (1976) described cultures and societies as either sex-positive (i.e., emphasizes the pleasurable, gratifying, rewarding, and non-reproductive aspects of sex) or sex-negative (i.e., perceives semen loss and sexual intercourse as a weakness and sexual asceticism is encouraged). Nevertheless, as societies have evolved, changed, and imbibed new customs, the attitudes and values regarding sexual interests, activity, and overall sexuality have also changed accordingly (Ayonrinde \& Bhugra, 2015).

Relative to the Western cultures, Asian and Middle Eastern cultures commonly adopt a higher restrictive view on sexual issues. In these cultures, discussion on sex has always been and remains a taboo subject (Baazeem, 2016; Ho, Singam, Hong, \& Zainuddin, 2011). Thus, it is reasonable to perceive that cultural factors may influence an individual's expression of distress as a result of his/her sexual dysfunction. For instance, Chinese males may feel embarrassed to discuss erectile dysfunction and choose to suffer in silence (Ho et al., 2011). Indeed, complaints of ejaculatory delay are more common in Asian populations when compared to those from the Europe, Australia, and the USA (Kalra, Tandon, \& Rao, 2014). Concerning the treatment of sexual disorders and specifically for paraphilic interests and behavior, the review by Kalra and colleagues (2014) observed that Asian patients are more likely to feel uncomfortable consulting healthcare professionals regarding their sexual problems. These patients are often feel anxious and unwilling to discuss their sexual (dys)functioning with the practitioners. Tamatea and colleagues (2011) argued that the cultural aspect seems to be a major barrier across processes of assessment, treatment, and reintegration with individuals with sexual problems. Therefore, it is reasonable to posit that compare to the Western populations, Eastern populations particularly the Asians may less likely to possess atypical or paraphilic interests in view of the sexual conservatism within their cultural background. Even if they do, Asians are less likely to openly admit their paraphilic interests and behavior compare to their Western counterparts. Such assertions have been found supportive in past cross-cultural studies (e.g., Abramson \& Imai-Marquez, 1982; Dang, Gorzalka, \& Brotto, 2019; Meston, Trapnell, \& Gorzalka, 1996). 
Interestingly, most empirical studies of paraphilias or paraphilic disorders have primarily involved samples recruited in clinical or forensic settings (e.g., Behrendt, Buhl, \& Seidl, 2002; Kafka \& Hennen, 2002; Marsh et al., 2010); little is known about the prevalence and nature of paraphilic interests and behavior in the general population, particularly from the Eastern hemisphere. Given that acting on some paraphilic interests (e.g., biastophilia, sexual sadism, pedophilia, frotteurism, and zoophilia) can violate laws or social norms, more research on the nonclinical population is desirable. Notably, recent research has found that paraphilic interests may be far more common than presumed (Ahlers, Schaefer, Mundt, Roll, Englert, Willich, \& Beier, 2011; Dawson, Bannerman, \& Lalumière, 2016) and that offender and nonoffender populations may be comparable (Williams, Cooper, Howell, Yuille, \& Paulhus, 2009). Ahlers and colleagues (2011) found that $64 \%$ of male participants from a German community reported at least one paraphilic interest, with the most frequent being voyeurism $(35 \%)$, fetishism (30\%), and sadism (22\%); they also found that paraphilic fantasies (59\%) were more commonly reported than paraphilic behaviors (44\%). Similarly, Joyal and Carpentier (2017) noted that nearly half of their sample of 1040 Canadian adults (46\%) acknowledged an interest in at least one paraphilic behavior, and about $34 \%$ had engaged in a paraphilic behavior at least once in their lives, with voyeurism (46\%) and fetishism (45\%) being the most common. In Baur and colleagues' (2016) study of 599018 to 33-year-old twins from a Finnish population cohort, $18 \%$ of the sample reported having at least one paraphilic interest or behavior, with voyeurism $(11 \%)$ and sexual masochism $(7 \%)$ being the most common.

Understanding paraphilic interests in a general population remains an important area not only from a public health perspective but also from a criminal justice standpoint. For instance, having an interest in paraphilic behavior that is illegal in nature (e.g., biastophilia [rape] or pedophilia [sex with underage children]) may pose a serious threat to the public. Besides, problematic sexual interests and behavior are associated with a number of harmful consequences, including heightened risk of sexually transmitted infections (Yoon, Houang, Hirschfield, \& Downing, 2016), interpersonal problems (Winder, Fedoroff, Grubin, Klapilová, Kamenskov, Tucker, et al., 2019), physical injuries (Carnes, 1991), and sexual (re)offending behavior (Chan, 2020a; Hanson \& Morton-Bourgon, 2005). In view of the potential high risk of adverse public health outcomes, it is worthwhile to understand this phenomenon in Hong Kong, especially the factors associated with paraphilic interests, to effectively identify and intervene in a timely manner on behalf of those who are at greatest risk for such outcomes. By providing an assessment of the psychosocial factors of paraphilia through the lens of criminology, the findings of this study add to our knowledge in this area and contribute to the literature.

\section{Theoretical Background}

The relationship between low self-control and deviant sexual interests (e.g., paraphilic interests) has been noted in the literature. According to Gottfredson and Hirschi (1990), self-control theory (a.k.a. the general theory of crime) postulates that individuals with low self-control are more likely to engage in deviant and offending behavior in search of immediate gratification without considering the potential consequences. Muraven and colleagues (2006) asserted that low-self-control individuals often manifest six key characteristics: they are impulsive, selfcentered, short-tempered, and risk-seekers, and they prefer simple over complex tasks and physical over mental activities. The developmental background of these individuals is characterized by early criminogenic exposure that did not allow them to develop sufficient control over their behavior. This personality trait, formed between the ages of 6 and 10, has been argued to be remain extremely stable over the rest of one's life (Hirschi \& Gottfredson, 1994), regardless of demographic characteristics such as age, gender, culture, and social class). Empirical research has indicated that most deviant sexual interests and behaviors (e.g., sexual exposure [exhibitionism], crossdressing [transvestic fetishism]) are often characterized by the same underlying characteristics: poor impulse control, the need for immediate gratification, risk and sensation seeking, self-centeredness, and inability to see the long-term consequences of current actions (i.e., low self-control; Love, 2006). Specifically, Love (2006) found that low self-control was predictive of likelihood of involvement in illicit or deviant sexual behavior and crime. In addition, the literature has documented positive relationships between traits of low self-control and more violent types of deviant sexual behavior (e.g., sexual aggression, sexual homicide) (Ha \& Beauregard, 2016; Healey \& Beauregard, 2016). Sexual offenders lower in self-control have been reported to exhibit behaviors that were impulsive, risky, insensitive, short-sighted, physical, and aggressive. However, DeLisi and Wright (2014) claimed that the relationship between low self-control and sexual homicide may be curvilinear: sexual murderers who are low in self-control may be more disorganized in the nature of their offense, while those high in selfcontrol may appear to be more organized. 
Agnew's (2002) general strain theory hypothesizes that individuals who are experiencing strain (e.g., stressors) may interact with their individual characteristics to intensify the risk of engaging in maladaptive behaviors, including deviant or paraphilic activities. These negative coping strategies are often used in response to adverse events, treatment, or conditions. Agnew (1992) posited that negative emotions (e.g., frustration, rejection, ridicule, isolation, depression, and anger) are typically stimuli for action that elicits a progression from strain to deviant behavior (e.g., paraphilic interests and activities). Thus, exposure to these strains may generate negative emotions that demand corrective action (Agnew, Brezina, Wright, $\&$ Cullen, 2002). Such corrective action aims to restore an individual's emotional equilibrium (i.e., positive emotions, such as excitement, control, and satisfaction). Paraphilic interests and subsequent behaviors may bestow a powerful sense of positive emotions, which may become habitual and dominate an individual's social and interpersonal relationships (Hickey, 2002; Yakeley \& Wood, 2014). Levine and colleagues (1990) argued that paraphilias are a form of defense against dysphoric feelings (e.g., strains), in which paraphilic interests and activities are regarded as a form of retreat from unwanted emotions such as anxiety and sadness.

The behavioral learning approach, as exemplified by Sutherland's (1947) differential association theory and Akers's (1985) social learning theory, theorizes that deviant and criminal behavior is learned through close social interaction with family and peers in the forms of reinforcement and reward or punishment. Differential reinforcement or punishment generally refers to the net balance of anticipated social and/or nonsocial rewards and costs related to different behaviors (Akers, 1997). For instance, social reinforcement involves "not just the direct reactions of others present while an act is performed, but also the whole range of tangible and intangible rewards valued in society and its subgroups" (Akers, 1997, p. 55), such as positive facial expressions, verbal approval from significant others, and financial rewards. In contrast, nonsocial reinforcements are "unconditioned positive and negative effects of physiological and psychological stimuli" (Akers, 1998, p. 71), such as the psychophysiological effects of a stimulant. Bandura (1973) asserted that similar to other attitudes and behavior, deviant and criminal behavior is learned from role models, as the imitation of observed behavior is a key behavioral learning process. The likelihood that an individual will learn an observed behavior increases when he/she expects incentives. Nevertheless, the effect of such exposure varies widely according to the frequency, duration, intensity, and priority of different associations (Akers, 1998). Chan (2015) and Chan and colleagues (2011) suggested that childhood and/ or adolescent experiences of physical and/or sexual abuse or of witnessing domestic violence predisposed an individual to subsequent adverse consequences (e.g., sexual deviant and criminal behavior). Although primary social groups (e.g., family and peers) are likely to have a strong influence on the behavioral learning process, Warr (2002) asserted that secondary and reference groups (e.g., the school system, colleagues and work groups, mass media, the Internet, and computer and mobile games) can be equally pertinent to normative definitions (e.g., values, norms, beliefs, and attitudes) in the learning process. According to Arrigo and Purcell (2001), individuals who engage in paraphilic fantasies or have a strong interest in paraphilic activities are compelled to actualize their fantasies, and they experience an exhilarating rush of carnal satisfaction and an increased need for stimulation every time the behavior is initiated. This paraphilic behavior may function as a reinforcer through classical conditioning and cycle back into their fantasy system, resulting in behavioral escalation and habituation. The use of alcohol and drugs has been found to function as a facilitator, exacerbating paraphilic interests and behavioral manifestations (Hickey, 2002). A strong dependency on alcohol and drugs is likely to escalate until the individual becomes desensitized to the facilitator.

Similarly, positive relationships between risky sexual behavior and paraphilic interests and activities have been reported in the literature. Consistent with a number of theories of sexual offending, Lalumière and colleagues (2005) postulated that an individual's paraphilic interests and behavior are likely to be influenced by their degree of impulsivity or likelihood of engaging in sexual and nonsexual risky behavior. Several other studies have also reported that risk-taking and impulsivity play significant roles in the expression of paraphilic interests and activities (e.g., Kafka, 1997, 2001; Långström \& Seto, 2006; Marshall, 2007). Low levels of general inhibition, consequent to greater degrees of risk-seeking and impulsivity, are likely to facilitate the development of atypical sexual interests (e.g., paraphilic interests; Dawson et al., 2016). Kafka (2001) stated that a high sex drive and a strong preference for novelty may precede or contribute to the development of paraphilic interests, whereby some individuals become habituated to conventional sexual partners and activities. Empirical studies have found that individuals diagnosed with paraphilias are more likely to report more risky sexual behaviors, such as a high number of sexual partners, high rates of sexual behavior, and strong sexual appetites and preoccupations (Chan, 2019a; Kafka, 2009; Kafka \& Hennen, 2003; Långström \& Hanson, 2006). Hence, the development of paraphilic interests may be associated with the individual's risk-taking and impulsivity tendencies.

Social control theory, developed by Hirschi (1969), postulates that deviance or crime occurs as a result of weak social bonds with conventional society (e.g., parents, 
prosocial peers, and school). Individuals with stronger social bonds are less likely to engage in deviant or criminal activities, including deviant sexual activities (e.g., paraphilic activities). This theory includes four core social bond elements: (1) attachment, (2) commitment, (3) involvement, and (4) belief. Attachment is generally defined as emotional or affective ties to parents, peers, and school. Commitment refers to an individual's investment in prosocial behavior, including a willingness to do what is promised and respect for the expectations of others regarding fulfilling one's promises. Involvement refers to active participation in prosocial activities (e.g., sports, religious practices, and community services). Belief is defined as recognition of the moral validity of societal regulations and norms. These four social bond elements are strongly correlated, and their combined effect may be stronger than their individual effects (Hirschi, 1969). Laundra and colleagues (2002) suggested that attachment and commitment to prosocial individuals and activities may increase an individual's morality belief, which may reduce their propensity to engage in deviant and criminal behavior. Bogaerts and colleagues (2006) found that weaker parental ties were generally noted in a group of exhibitionists compared with nonexhibitionists. Some sexual offending theories posit that feelings of inadequacy, the outcome of a lack of social bonding with prosocial others (i.e., parental bonding during childhood and adolescence), may encourage an individual to retreat into a world of fantasy and social isolation (Burgess, Hartman, Ressler, Douglas, \& McCormack, 1986; Hickey, 2002). Over time, fantasies may become more erotic and violent through the incorporation of paraphilic fetishes, rituals, and/or unusual and sexually charged objects as stimuli for sexual gratification.

Individuals' routine activities and lifestyle choices, as situational mechanisms, have also been frequently used to explain deviant and criminal behavior, including deviant sexual interests and behavior. Cohen and Felson (1979) argued in their routine activity theory that the likelihood of a crime's occurring is generally influenced by the convergence in time and space of three key features in the daily routines of the individuals involved: (1) a motivated or potential offender, (2) an attractive or suitable target, and (3) an ineffective or absent guardian to protect against a violation. It should be noted that the lack of any of these features reduces the likelihood of a potential crime (Felson \& Cohen, 1980). Although this theory was initially developed to explain victimization as an outcome of legitimate and routine daily activities that expose poorly guarded targets to potential offenders in close proximity, it was later extended to describe deviant and offending behavior. Put simply, an individual's probability of developing sexually deviant interests (e.g., paraphilic interests) and of subsequently engaging in deviant and criminal behavior is generally associated with their specific daily activities (e.g., deviant peer association), lifestyle (e.g., criminogenic living environment), and status (e.g., personal characteristics). For example, young people who spend considerable time in "unstructured socializing" with deviant peers and without adult supervision are likely to be at a heightened risk of engaging in deviant and criminal activities (Osgood, Wilson, O’Malley, Bachman, \& Johnston, 1996). Tangible and intangible rewards (e.g., reputation or status within a group) may also encourage initial and persistent participation in deviant and criminal activities (e.g., group sexual deviant and offending behavior;' t Hart-Kerkhoffs, Vermeiren, Jansen, \& Doreleijers, 2011). Some paraphilic activities are commonly performed in a group setting (e.g., group voyeurism, exhibitionism, and transvestic fetishism). Furthermore, criminogenic environments (e.g., domestic and community criminogenic exposures) have been consistently reported to be correlated with deviant sexual and nonsexual interests and offending behavior (Chan, Lo, Zhong \& Chui, 2015a, b; Hewitt \& Beauregard, 2014).

\section{The Present Study}

Based on the literature, the importance of this study is threefold. It is arguably the first empirical study to explore the prevalence of the paraphilic interests of a large group of young male and female adults in Hong Kong. This exploratory study examines the psychosocial factors associated with general and subtypes of paraphilic interest through tests of several mainstream theoretical principles and concepts. It also explores the sex distribution of general and different subtypes of paraphilic interest. This study focuses on the applicability of these theoretical constructs to explaining the paraphilic interests of a sample of Chinese young adults. It is noteworthy that a recent study by Bartova and colleagues (2020) indicated a significantly positive association between paraphilic interests and subsequent paraphilic behavior. It was argued that the high prevalence in some paraphilic interests and patterns might render their pathologization problematic in subsequent behavioral manifestation. Carvalho (2018) asserted that paraphilic sexual interests can be considered, to a certain extent, a motivational factor in some sexual offenses (e.g., biastophilia, pedophilia, and sadism). Hence, it is important that the findings of this study can inform practice (e.g., preventive measures) through the identification of significant psychosocial factors for different types of paraphilic interest. Well-timed strategic interventions can reduce young adults' likelihood of engaging in paraphilic activities, which may run a risk in progressing to more criminally-oriented paraphilic activities (e.g., pedophilia, 
biastophilia). The following research hypotheses are proposed for this study.

Hypothesis 1:There are sex differences in the mean levels of various types of paraphilic interest (i.e., general, voyeurism, exhibitionism, scatologia, fetishism, transvestic fetishism, frotteurism, sadism, masochism, biastophilia, urophilia, scatophilia, hebephiliac, pedophilia, and zoophilia) and psychosocial factors (i.e., self-control, negative temperament, alcohol and drug use, risky sexual behavior, social bonds, and perceived neighborhood disorganization).

Hypothesis 2:Psychosocial factors are associated with different types of paraphilic interest, even when controlling for the young adults' demographic characteristics (i.e., age, sex, religiosity, and marital status), such that low levels of self-control and social bonds and high levels of negative temperament, alcohol and drug use, risky sexual behavior, and perceived neighborhood disorganization are associated with all types of paraphilic interest.

\section{Methods}

\section{Participants and Procedure}

In this study, 1171 participants aged at least 18 years were recruited from eight public (i.e., government-funded) and two private universities in Hong Kong. Participants were approached randomly within university compounds (e.g., student cafeterias, reading corners, libraries, and common areas) with no preset time period (i.e., about 2 years), from September 2018 through April 2020. Ethical approval was obtained from the university's institutional review board. The participants' informed consent was obtained before copies of the paper-based questionnaire were administered. They completed the questionnaire in private without any interruption. Their participation in this study was completely voluntary and anonymous. No monetary incentive was provided. They were told that their responses would be kept confidential and used only for research purposes. The participants required $25 \mathrm{~min}$ on average to complete the questionnaire. The response rate for this survey was about $90 \%$.

Most of the participants in this study, $58.5 \%$, were females, with the remaining $41.5 \%$ males. The participants averaged 20.95 years of age $(S D=2.01$; range $=18-40)$, with a slight sex difference (males: $M=21.24, S D=2.14$; females: $M=20.75, S D=1.88 ; t=3.98, p<0.001$ ). A large majority of the participants $(88.6 \%)$ were local Hong Kongers, with the remaining participants from either mainland China $(8.5 \%)$ or other countries $(2.9 \%$; e.g., Canada, Macau, Japan, Australia, and the USA). About two thirds of the participants $(62.1 \%)$ were single, more than half $(57.6 \%)$ had obtained post-secondary school education, and nearly three quarters $(73.1 \%)$ reported having no religious beliefs (Table 1).

\section{Measures}

In this study, a collection of self-reported measures was used to explore (a) the prevalence of general and 14 subtypes of paraphilic interest among the participants, (b) the sex differences in the general and 14 subtypes of

Table 1 Sample demographic characteristics $(N=1171)$

\begin{tabular}{llr}
\hline Variable & Number & Percentage \\
\hline Sex & & $(N=1,160)$ \\
$\quad$ Male & 481 & $41.5 \%$ \\
$\quad$ Female & 679 & $58.5 \%$ \\
Country of origin & & $(N=1,154)$ \\
$\quad$ Hong Kong & 1,023 & $88.6 \%$ \\
$\quad$ Mainland China & 98 & $8.5 \%$ \\
$\quad$ Others (e.g., Canada, Macau, Japan, Australia, and USA) & 33 & $(N=1,157)$ \\
Marital Status & & \\
$\quad$ Single & 718 & $(N=1,156)$ \\
$\quad$ Nonsingle & 439 & $62.1 \%$ \\
Highest education attainment & & $37.9 \%$ \\
$\quad$ Secondary school education & 492 & $42.4 \%$ \\
$\quad$ Post-secondary school education (e.g., associate degree/high diploma, and under- & 664 \\
$\quad$ graduate and postgraduate degrees) & & $57.6 \%$ \\
Religious belief & & $(N=1,154)$ \\
$\quad$ Without a religious belief & 844 & $73.1 \%$ \\
$\quad$ With a religious belief e.g., Christianity, Catholic, Buddhism, Muslim) & 310 & $26.9 \%$ \\
\hline
\end{tabular}


paraphilic interest, and (c) the effects of psychosocial factors on general and 14 subtypes of paraphilic interest. The questionnaire with these measures was printed in both English and Chinese for participants with different language needs. To accommodate the local Chinese population, the English-written measures were first translated into Chinese by an experienced and academically qualified English-to-Chinese translator. The Chinese version was then back-translated into English to ensure face validity and compared with the original English version to confirm consistency.

\section{Paraphilias Scale}

Forty items measured on a 7-point Likert scale $(-3=$ very repulsive, $+3=$ very arousing) were used to assess the participants' interest in paraphilic activities (Seto, Lalumière, Harris, \& Chivers, 2012). The total score for the paraphilias scale ranged from -120 to +120 , where a higher score denoted a greater interest in paraphilic activities. Of the 40 items, 32 referred to 14 subtypes of paraphilic interest. These subtypes are (a) voyeurism (sexual arousal involving the observation of an unsuspecting individual who is naked, undressing, or engaging in sexual activity; one item), (b) exhibitionism (sexual arousal involving the exposure of one's genitals to an unsuspecting individual; one item), (c) scatologia (sexual arousal involving the making of unsolicited and obscene telephone calls; one item), (d) fetishism (sexual arousal involving nonliving objects such as shoes and undergarments; three items), (e) transvestic fetishism (sexual arousal involving cross-dressing activities; two items), (f) frotteurism (sexual arousal involving activities of touching and rubbing against an unsuspecting individual; one item), (g) sadism (sexual arousal involving activities of inflicting harm and humiliation on another individual; six items), (h) masochism (sexual arousal involving activities of being humiliated, beaten, bound, or otherwise made to suffer; six items), (i) biastophilia (sexual arousal involving having sexual intercourse with a nonconsenting individual; two items), (j) urophilia (sexual arousal involving contact with urine; two items), (k) scatophilia (sexual arousal involving contact with feces; two items), (l) hebephilia (sexual arousal involving having sexual intercourse with pubescent children; two items), (m) pedophilia (sexual arousal involving having sexual intercourse with prepubescent children; two items), and (n) zoophilia (sexual arousal involving having sexual intercourse with animals; one item). Higher scores indicated a greater interest in the corresponding paraphilic activities. Sample items are as follows: "You are having your feet kissed, fondled, and touched" (fetishism), "You are spanking, beating, or whipping someone" (sadism), and "You are having sex with a boy below the age of 12" (pedophilia). It should be noted that two items in the measure were regarded as control items in the original study, as they were referred to interest in adult males and females (Seto et al., 2012). The Cronbach's $\alpha$ of this measure in this study was 0.98 $($ males $=0.98$, females $=0.98)$.

\section{Self-Control Scale}

The six core elements of self-control (i.e., risk-seeking, self-centeredness, impulsivity, volatile temper, preference for physical activities, and preference for simple tasks), as theorized in self-control theory, are widely known to be indicators of low self-control (Gottfredson \& Hirschi, 1990). The 23-item Low Self-Control Scale (LSCS) was adopted to measure the participants' levels of self-control (Grasmick, Tittle, Bursik, \& Arneklev, 1993). The LSCS was assessed on a 4-point Likert scale ( $1=$ strongly agree, $4=$ strongly disagree), with a total score ranging from 23 to 92, where a higher score signified greater self-control. Sample items are as follows: "I always do whatever brings me pleasure here and now, even at the cost of some distant goal," "When I am really angry, other people better stay away from me," and "Excitement and adventure are more important to me than security." The Cronbach's $\alpha$ of this measure in this study was 0.87 (males $=0.89$, females $=0.85$ ). This measure has been validated in Chinese and was used in studies conducted in Hong Kong and Macau, which was found to achieve acceptable inter-item reliability (above 0.70; e.g., Chan, 2019b, c and d; Chan \& Chui, 2017).

\section{Negative Temperament Scale}

To evaluate the participants' levels of negative emotions, eight items on a 4-point Likert scale $(1=$ strongly agree, $4=$ strongly disagree) were used (Tillyer \& Wright, 2014). The total score for this measure ranged from 8 to 32 , with a higher score indicating a more strongly negative temperament. Sample items are as follows: "I get stressed out easily," "I get upset easily," and "I frequently have mood swings." In this study, the internal consistency of this measure was 0.64 (males $=0.64$, females $=0.65)$. Although the Cronbach's $\alpha$ of this measure was below, but approaching, the acceptable level of 0.70 (Nunnally, 1978), this estimate should be studied cautiously and keeping in mind of the very limited utility of the Cronbach's $\alpha$, which primarily measures the "interrelatedness of the items" (Sijtsma, 2009). Straus and Kantor (2005) claimed that low internal consistency may also be due to highly skewed distributions of included items as this reduces "the size of the correlation between items and therefore also the alpha" (p. 25). This scale was used previously in another 
study with Hong Kong participants, and has achieved acceptable Cronbach's $\alpha$ value (i.e., 0.70; Chan, 2019b, $c$ and $d)$.

\section{Alcohol and Drug Use Scale}

An eight-item measure on a 6 -point Likert scale $(0=$ never, $5=20$ or more times) was adopted to assess the participants' alcohol and drug use over the past 30 days (Espelage, Low, Rao, Hong, \& Little, 2014) with a total score ranging from 0 to 40 , where a higher score indicated a higher frequency of alcohol and drug use. Sample items are as follows: "Drank wine or wine coolers (more than a sip or taste)," "Used marijuana (pot, hash, or reefer)," and "Smoked cigarettes." The Cronbach's $\alpha$ value of this measure in this study was 0.80 (males $=0.80$, females $=0.80)$. This measure was previously adopted in another study that recruited Hong Kong participants, with a high alpha coefficient value (i.e., 0.89; Chan, 2019c and d).

\section{Risky Sexual Behavior Scale}

A slightly modified version of the 23-item Sexual Risk Survey (SRS; Turchik \& Garske, 2009) was used in this study to assess the participants' level of involvement in risky sexual behavior over the past 6 months. This measure was dichotomized $(0=$ no, $1=$ yes $)$. The total score of the SRS ranged from 0 to 23 , with a higher score indicating greater involvement in risky sexual behavior. Sample items asked whether the participants had "Had an unexpected and unanticipated sexual experience," "Had anal sex without a condom," and "Had sex with someone he/she didn't know well or had just met." The Cronbach's $\alpha$ value of this measure in this study was 0.69 (males $=0.72$, females $=0.60$ ).

\section{Social Bonding Scale}

To measure the participants' conventional attachments and ties to their parents, peers, school, and society, the 18-item Social Bonding Scale (SBC; Chapple, McQuillan, $\&$ Berdahl, 2005) was adopted. The SBC was developed based on Hirschi's (1969) social control theory. Attachment to parents was separated into two separate latent constructs (i.e., parental dependence and parental bonding). Adopting 4-point ( $1=$ never, $4=$ many times; two items) and 5-point ( $1=$ strongly disagree, $5=$ strongly agree; 16 items) Likert scales, the total score of the SBC ranged from 18 to 38 , where a higher score denoted a stronger social bond. Sample items are as follows: "I share my thoughts and feelings with my mother," "I would like to be the kind of person my best friend is," and "I have lots of respect for the police." In this study, the internal consistency of this measure was 0.72 (males $=0.72$, females $=0.71$ ). This scale has been validated in Chinese and was used in studies with samples recruited from Hong Kong and Macau, with acceptable internal consistency (above 0.70; e.g., Chan, 2019b, c and d; Chan \& Chui, 2012, 2013, 2015).

\section{Perceptions of Neighborhood Disorganization Scale}

Five items on a 4-point Likert scale ( $1=$ strongly agree, $4=$ strongly disagree) were used to assess the participants' perceptions of neighborhood disorganization in their living environment (Posick, 2013). The total score of this scale ranged from 5 to 20. Sample items are as follows: "There is a lot of fighting," "There is a lot of graffiti," and "There is a lot of crime in my neighborhood." These items were then reverse-coded so that higher scores would denote higher levels of perceived neighborhood disorganization. The Cronbach's alpha of this scale in this study was 0.93 (males $=0.93$, females $=0.92$ ). This scale was adopted in a previous study that sampled Hong Kong participants, with a high level of internal consistency (i.e., 0.93; Chan, 2019b, $\mathrm{c}$ and d).

\section{Analytic Strategy}

In this study, Mann-Whitney $U$ tests were used to examine the sex differences in the general and 14 subtypes of paraphilic interest (i.e., voyeurism, exhibitionism, scatologia, fetishism, transvestic fetishism, frotteurism, sadism, masochism, biastophilia, urophilia, scatophilia, hebephilia, pedophilia, and zoophilia) as the distribution of these variables was highly skewed; while independent sample $t$ tests were used to explore the sex differences in the psychosocial factors (i.e., self-control, negative temperament, alcohol and drug use, risky sexual behavior, social bonding, and perceived neighborhood disorganization). Next, Spearman's rho correlations were tabulated to explore the interrelatedness of general and 14 subtypes of paraphilic interest. Lastly, ordinary least squares (OLS) regressions were adopted to examine the effects of different psychosocial factors on general and 14 subtypes of paraphilic interest while controlling for the participants' demographic characteristics (i.e., age, religiosity, and marital status). The OLS regression model was used as it allows to estimate values of a continuous response variables using more than one explanatory variables and to identify the strength of the relationships between these variables. The participants' religiosity was assessed using a 6-point Likert scale asking how religious they perceived themselves to be $(1=$ not at all, $6=$ very strongly $)$. Pearson correlations of the tested constructed were computed. No correlation at or above 0.70 was found, denoting no collinearity. The significance level was set at 0.05 . 


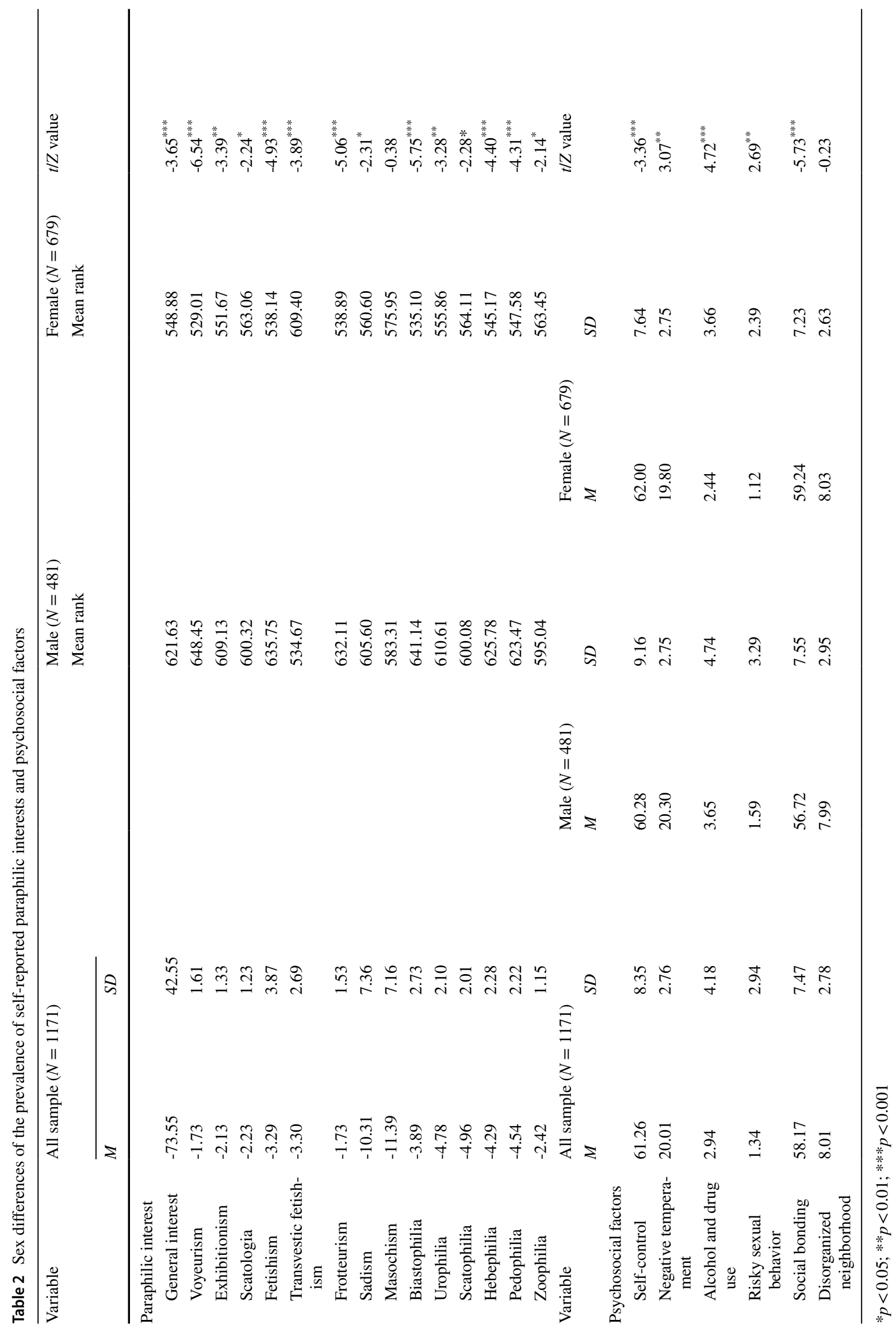




\section{Ethical Considerations}

This study was approved by the ethical committee of the author's university. The participants could end their participation, contact the primary investigator, and/or receive professional counseling at any time. Data were collected anonymously, and no identifying personal details were recorded.

\section{Results}

\section{Sex Differences in Paraphilic Interests and Psychosocial Factors}

Table 2 illustrates the mean scores for general and 14 subtypes of paraphilic interest and the psychosocial factors of the male and female participants. The male participants reported significantly higher levels of general paraphilic interests $(U=141,960.00, Z=-3.65, p<0.001)$, voyeurism $(U=128,634.00, Z=-6.54, p<0.001)$, exhibitionism $(U=144,470.50, Z=-3.39, p=0.001)$, scatologia $(U=151,689.00, Z=-2.24, p=0.025)$, fetishism $(U=134,677.50, Z=-4.93, p<0.001)$, frotteurism $(U=135,462.50, Z=-5.06, p<0.001)$, sadism $(U=149,640.50, Z=-2.31, p=0.021)$, biastophilia $(U=132,614.00, Z=-5.75, p<0.001)$, urophilia ( $U=146,694.00, Z=-3.28, p=0.001)$, scatophilia ( $U=152,284.50, Z=-2.28, p=0.022)$, hebephilia ( $U=139,441.50, Z=-4.40, p<0.001)$, pedophilia $(U=141,077.50, Z=-4.31, p<0.001)$, and zoophilia ( $U=152,063.00, Z=-2.14, p=0.033)$ than the female participants. The female participants only scored significantly higher than the male participants for transvestic fetishism $(U=141,089.50, Z=-3.89, p<0.001)$. Relative to the female participants, the male participants reported significantly higher levels of negative temperament $(t=3.07$, $p=0.002)$, alcohol and drug use $(t=4.72, p<0.001)$, and risky sexual behavior $(t=2.69, p<0.001)$. However, the female participants scored significantly higher for selfcontrol $(t=-3.36, p<0.001)$ and social bonding $(t=-5.73$, $p<0.001)$ than their male counterparts.

\section{Spearman's Rho Correlations of General and Subtypes of Paraphilic Interest}

Using Spearman's rho correlations, Table 3 presents the significant and positive relationships between the subtypes of paraphilic interest. The correlation coefficients for general paraphilic interest and the 14 subtypes of paraphilic interest for the total sample ranged from 0.43 to 0.94 . The correlation coefficients for the male and female participants similarly ranged from 0.36 to 0.93 .

\section{Effects of Psychosocial Factors on General and Subtypes of Paraphilic Interest}

OLS regressions were computed to examine the correlational effects of psychosocial factors on the participants' general and 14 subtypes of paraphilic interest while controlling for their demographic characteristics (i.e., age, sex, religiosity, and marital status). Table 4 indicates that all of the OLS regression models were significant. Interestingly, the participants' levels of self-control $(B=-0.80, S E=0.15$, $p<0.001)$, negative temperament $(B=1.16, S E=0.44$, $p=0.009)$, alcohol and drug use $(B=0.92, S E=0.32$, $p=0.004)$, risky sexual behavior $(B=2.14, S E=0.49$, $p<0.001)$, social bonding $(B=-0.40, S E=0.17$, $p<0.001$ ), and perceived neighborhood disorganization $(B=1.81, S E=0.44, p<0.001)$, as well as being younger $(B=-1.84, S E=0.59, p=0.002)$, were significantly associated with their overall paraphilic interest.

Psychosocial factors were also found to have significant correlational effects on different subtypes of paraphilic interest. Self-control was significantly associated with all paraphilic interest subtypes: voyeurism $(B=-0.03$, $S E=0.01, p<0.001)$, exhibitionism $(B=-0.03$, $S E=0.01, p<0.001)$, scatologia $(B=-0.02, S E=0.01$, $p<0.001)$, fetishism $(B=-0.05, S E=0.02, p=0.001)$, transvestic fetishism $(B=-0.04, S E=0.01, p<0.001)$, frotteurism $(B=-0.02, S E=0.01, p<0.001)$, sadism $(B=-0.12, S E=0.03, p<0.001)$, masochism $(B=-0.12, S E=0.03, p<0.001)$, biastophilia $(B=-0.05, S E=0.01, p<0.001)$, urophilia $(B=-0.05$, $S E=0.01, p<0.001)$, scatophilia $(B=-0.04, S E=0.01$, $p<0.001)$, hebephilia $(B=-0.05, S E=0.01, p<0.001)$, pedophilia $(B=-0.05, S E=0.01, p<0.001)$, and zoophilia $(B=-0.02, S E=0.01, p<0.001)$. Similarly, the participants' perceived neighborhood disorganization was significantly and positively correlated with all subtypes of paraphilic interest: voyeurism $(B=0.05$, $S E=0.02, p=0.003)$, exhibitionism $(B=0.05$, $S E=0.01, p=0.001)$, scatologia $(B=0.05, S E=0.01$, $p<0.001)$, fetishism $(B=0.12, S E=0.04, p=0.005)$, transvestic fetishism $(B=0.11, S E=0.03, p<0.001)$, frotteurism $(B=0.06, S E=0.02, p<0.001)$, sadism $(B=0.30, S E=0.08, p<0.001)$, masochism $(B=0.26$, $S E=0.08, p=0.007)$, biastophilia $(B=0.09, S E=0.03$, $p=0.001)$, urophilia $(B=0.08, S E=0.02, p<0.001)$, scatophilia $(B=0.09, S E=0.02, p<0.001)$, hebephilia $(B=0.12, S E=0.02, p<0.001)$, pedophilia $(B=0.10$, $S E=0.02, p<0.001)$, and zoophilia $(B=0.05, S E=0.01$, $p<0.001)$.

With the exceptions of exhibitionism, transvestic fetishism, and hebephilia, all 14 subtypes of paraphilic 


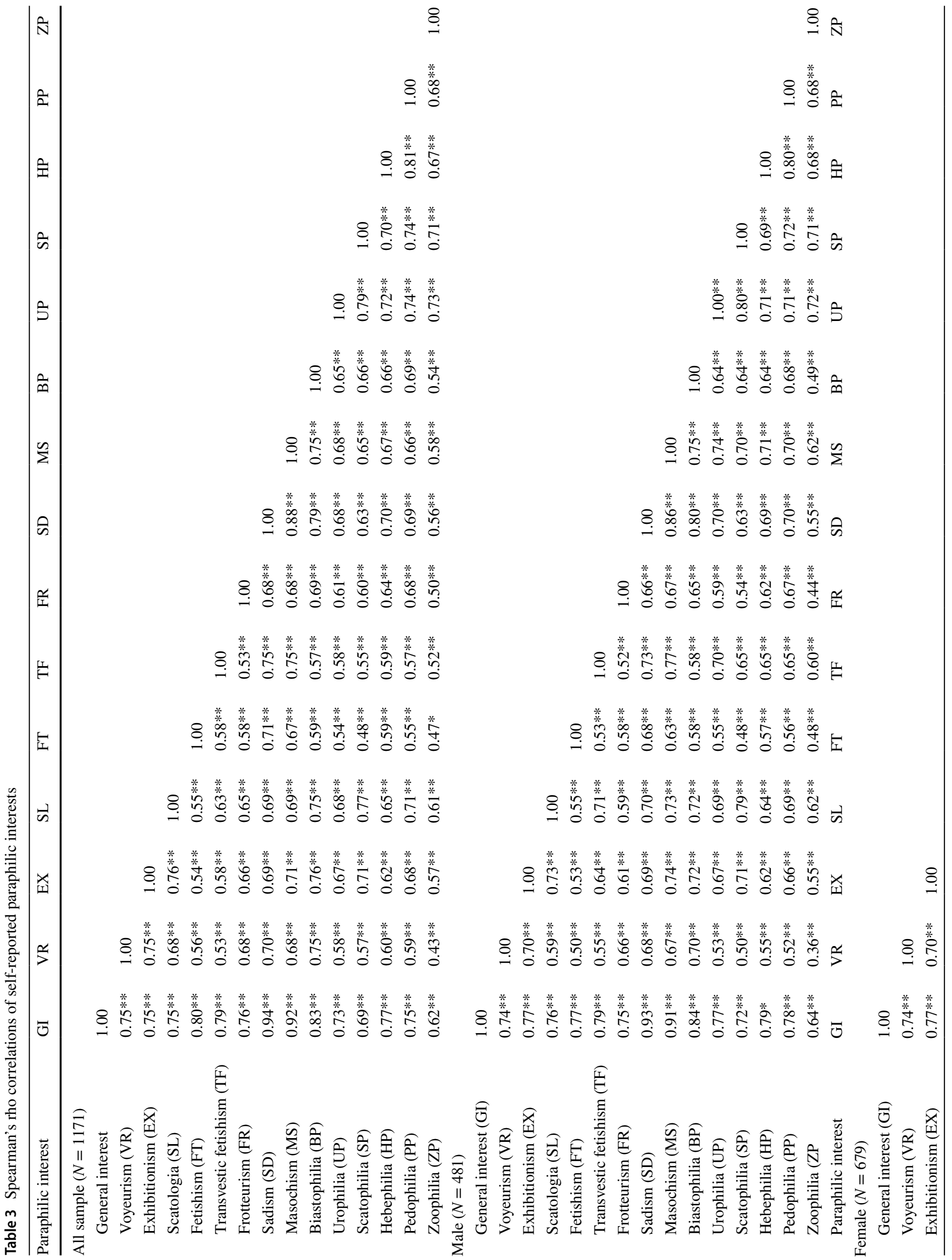




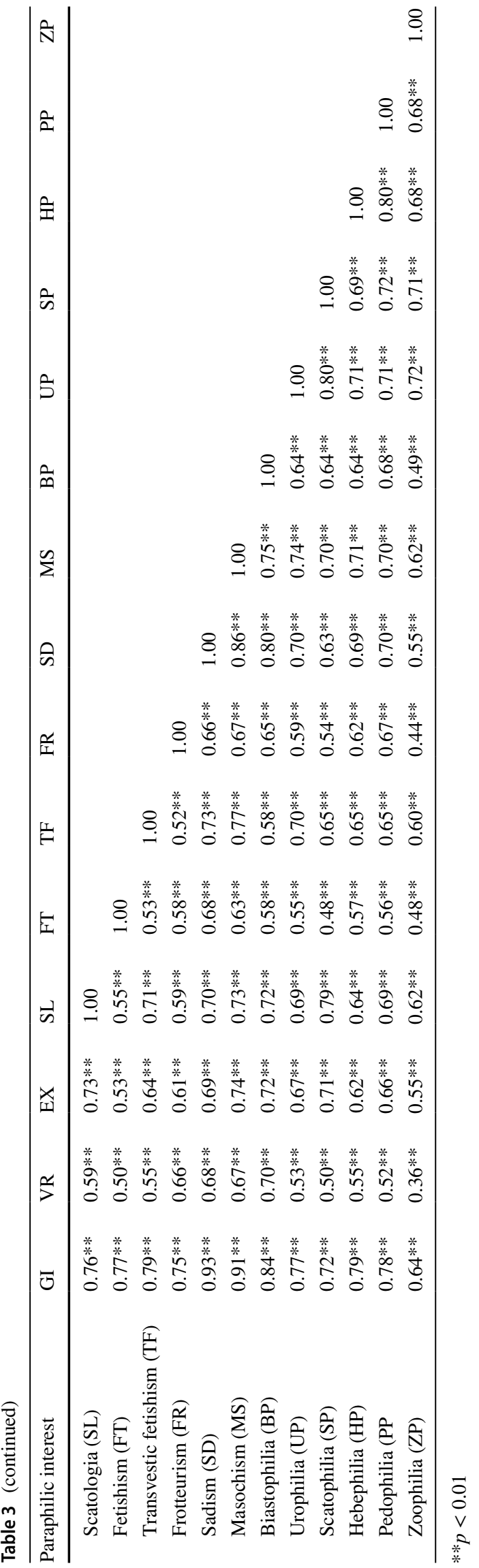

interest were significantly and positively correlated with the participants' alcohol and drug use: voyeurism $(B=0.03$, $S E=0.01, p=0.025)$, scatologia $(B=0.03, S E=0.01$, $p=0.003)$, fetishism $(B=0.06, S E=0.03, p=0.036)$, frotteurism $(B=0.02, S E=0.01, p=0.047)$, sadism $(B=0.14, S E=0.06, p=0.015)$, masochism $(B=0.15$, $S E=0.06, p=0.008)$, biastophilia $(B=0.06, S E=0.02$, $p=0.009)$, urophilia $(B=0.04, S E=0.02, p=0.022)$, scatophilia $(B=0.04, S E=0.02, p=0.030)$, pedophilia $(B=0.05, S E=0.02, p=0.002)$, and zoophilia $(B=0.02$, $S E=0.01, p=0.012)$. The participants' risky sexual behavior was found to have significant positive relationships with their interest in voyeurism $(B=0.04, S E=0.02$, $p=0.025)$, exhibitionism $(B=0.07, S E=0.02, p<0.001)$, fetishism $(B=0.16, S E=0.05, p<0.001)$, transvestic fetishism $(B=0.10, S E=0.03, p=0.002)$, frotteurism ( $B=0.07, S E=0.02, p<0.001)$, sadism $(B=0.51$, $S E=0.09, p<0.001)$, masochism $(B=0.39, S E=0.09$, $p<0.001)$, biastophilia $(B=0.14, S E=0.03, p<0.001)$, and zoophilia $(B=0.03, S E=0.01, p=0.013)$.

The level of negative temperament in the participants was found to be significantly correlated with their interest in exhibitionism $(B=-0.05, S E=0.01, p<0.001)$, scatologia $(B=0.03, S E=0.01, p=0.049)$, fetishism ( $B=0.12, S E=0.04, p=0.005)$, urophilia $(B=0.09$, $S E=0.02, p<0.001)$, scatophilia $(B=0.09, S E=0.02$, $p<0.001)$, hebephilia $(B=0.09, S E=0.03, p<0.001)$, pedophilia $(B=0.10, S E=0.02, p<0.001)$, and zoophilia $(B=0.06, S E=0.01, p<0.001)$. Finally, social bonding significantly predicted only voyeurism $(B=-0.02$, $S E=0.01, p=0.001)$, scatologia $(B=-0.01, S E=0.01$, $p=0.005)$, fetishism $(B=-0.04, S E=0.02, p=0.021)$, frotteurism $(B=-0.01, S E=0.01, p=0.044)$, sadism $(B=-0.08, S E=0.03, p=0.009)$, biastophilia $(B=-0.03$, $S E=0.01, p=0.026)$, and hebephilia $(B=-0.03, S E=0.01$, $p=0.003)$.

In terms of the participants' demographic characteristics, being younger was significantly associated with their interest in voyeurism $(B=-0.05, S E=0.02$, $p=0.024)$, exhibitionism $(B=-0.05, S E=0.02$, $p=0.008)$, scatologia $(B=-0.07, S E=0.02, p<0.001)$, transvestic fetishism $(B=-0.08, S E=0.04, p=0.046)$, frotteurism $(B=-0.07, S E=0.02, p=0.001)$, sadism $(B=-0.22, S E=0.10, p=0.032)$, masochism $(B=-0.28, S E=0.10, p=0.007)$, biastophilia $(B=-0.10, S E=0.04, p=0.007)$, urophilia $(B=-0.11$, $S E=0.03, p<0.001)$, scatophilia $(B=-0.10, S E=0.03$, $p=0.001)$, hebephilia $(B=-0.12, S E=0.03, p<0.001)$, pedophilia $(B=-0.09, S E=0.03, p=0.005)$, and zoophilia $(B=-0.06, S E=0.02, p=0.001)$. Being a male was a significant predictor of having an interest in voyeurism ( $B=0.52, S E=0.10, p<0.001)$, fetishism $(B=0.81, S E=0.23, p=0.001)$, frotteurism $(B=0.41$, 


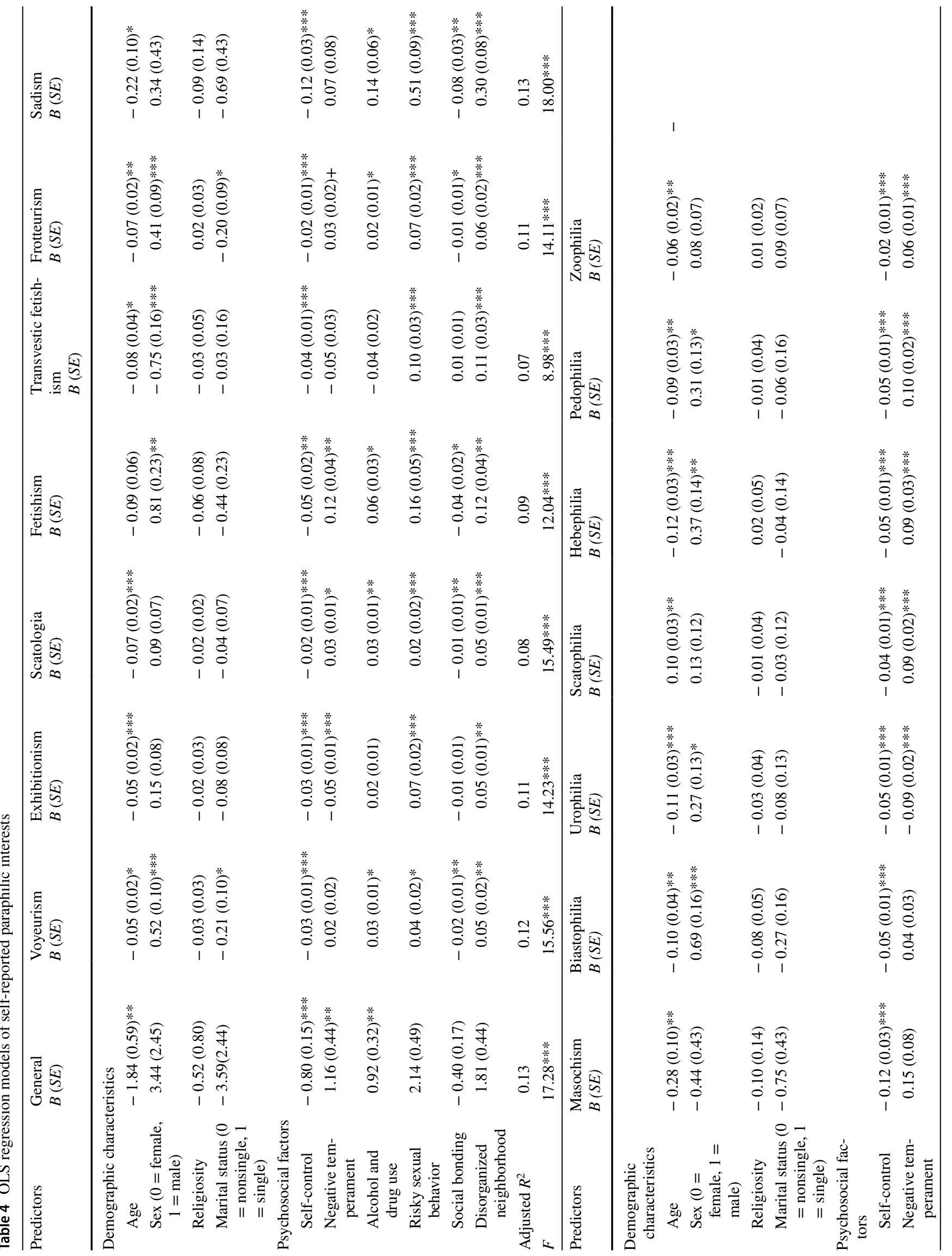


$S E=0.09, p<0.001)$, biastophilia $(B=0.69, S E=0.16$, $p<0.001)$, urophilia $(B=0.27, S E=0.13, p=0.032)$, and hebephilia $(B=0.37, S E=0.14, p=0.007)$, while transvestic fetishism $(B=-0.75, S E=0.16, p<0.001)$ was significantly associated with being a female. Lastly, being non-single was only significantly correlated with having an interest in voyeurism $(B=-0.21, S E=0.10$, $p=0.031)$ and frotteurism $(B=-0.20, S E=0.09$, $p=0.031)$.

\section{Discussion}

Paraphilic interest is broadly defined as sexual arousal from one or more atypical sexual activities (e.g., exposing one's genitals to nonconsenting others) or targets (e.g., prepubescent children). It should be noted that having an interest in some paraphilic behavior may result in illegitimate outcomes (e.g., biastophilia [rape], pedophilia [sex with underage children]), which may pose a serious risk to the public. This study is significant not only for its contribution to the growing literature on the topic but also, and more importantly, for its advancement of knowledge through research on an underresearched population: Hong Kong young adults. The study had two main aims, as follows: (1) to explore sex differences at the mean levels of general and 14 subtypes of paraphilic interest (i.e., voyeurism, exhibitionism, scatologia, fetishism, transvestic fetishism, frotteurism, sadism, masochism, biastophilia, urophilia, scatophilia, hebephilia, pedophilia, and zoophilia) and psychosocial factors (i.e., self-control, negative temperament, alcohol and drug use, risky sexual behavior, social bonds, and perceived neighborhood disorganization); (2) to investigate whether the relationships between different types of paraphilic interests and psychosocial factors hold when controlling for demographic characteristics (i.e., age, sex, religiosity, and marital status). Overall, the male participants reported significantly more general paraphilic interests, voyeurism, exhibitionism, scatologia, fetishism, transvestic fetishism, frotteurism, sadism, biastophilia, urophilia, scatophilia, hebephilia, pedophilia, and zoophilia than the female participants, while the female participants reported significantly more transvestic fetishism than their male counterparts. Relative to the female participants, the male participants reported significantly higher levels of negative temperament, alcohol and drug use, and risky sexual behavior but lower levels of self-control and social bonds. Thus, overall, the male participants were generally found to possess a higher tendency to have paraphilic interests than the female participants.

Several noteworthy findings regarding the effects of psychosocial factors on the probability of having paraphilic interests warrant further discussion; these provide support for various criminological theoretical propositions that explain 
paraphilic interests. The findings indicate that the approaches adopted to identify the influence of self-control (i.e., low selfcontrol), general strain (i.e., negative temperament), learning (i.e., alcohol and drug use, and risky sexual behavior), social control (i.e., social bonds), and routine activity and lifestyle (i.e., perceived neighborhood disorganization) were useful in explaining the general paraphilic interests of Hong Kong young adults. Put differently, having low self-control and weak social bonds, consuming alcohol and drugs, engaging in risky sexual behavior, having more negative emotions, and perceiving one's neighborhood to be criminogenic were noted to be strong predictors of an individual's tendency to have a general interest in paraphilic activities. It is also interesting to note that having low self-control and living in a criminogenic neighborhood were found to be significantly associated with having all subtypes of paraphilic interest. The low self-control theoretical proposition hypothesizes that individuals with low self-control are more likely to engage in deviant and offending behavior for their immediate satisfaction without considering the potential adverse consequences (Gottfredson \& Hirschi, 1990). Low selfcontrol has long been recognized by cross-cultural studies as a ubiquitous predictor of deviant and offending behavior (e.g., Chan, 2019b and c; Chan \& Chui, 2017; Gottfredson, 2009; Sacarellos, Wright, Almosaed, Moghrabi, Bashatah, $\&$ Morgan, 2016). However, the routine activity and lifestyle approach postulates that individuals who are exposed to a criminogenic environment (e.g., living in a crime-prone neighborhood) are more likely to absorb pro-deviance norms and values, which makes them more deviance-prone (Mills, 2003). Individuals' present or past exposure to deviant incidents (e.g., crime hotspots) might shape their perception of residing in a disorganized neighborhood. Coupled with their low self-control personality trait, this perception makes them more likely to develop an interest in all of the paraphilic activities examined in this study (i.e., voyeurism, exhibitionism, scatologia, fetishism, transvestic fetishism, frotteurism, sadism, masochism, biastophilia, urophilia, scatophilia, hebephilia, pedophilia, and zoophilia).

Additionally, an individual's alcohol and drug use and risky sexual behavior were significantly correlated with 11 and 10 specific paraphilic interests, respectively (alcohol and drug use: voyeurism, scatologia, fetishism, frotteurism, sadism, masochism, biastophilia, urophilia, scatophilia, pedophilia, and zoophilia; risky sexual behavior: voyeurism, exhibitionism, scatologia, fetishism, transvestic fetishism, frotteurism, sadism, masochism, biastophilia, and zoophilia). According to the learning approach, deviant interests and behavior (e.g., paraphilic interests) are often learned through differential association and behavioral imitation (Akers, 1997; Warr, 2002). For instance, masculine identity is often strengthened by engaging in risky and deviant behavior (Messerschmidt, 1993), and male culture and group membership usually stress risk-taking, aggression, toughness, and physical strength (Augustyn \& McGloin, 2013). Schreck and colleagues (2004) posited that individuals are more inclined to possess deviant interests and to engage in risky and deviant behavior if they spend considerable time in "unstructured socializing" (e.g., consuming alcohol and taking illicit drugs) with their deviant peers. Studies have also found that individuals who engage in risky sexual behavior (e.g., having multiple sexual partners, a strong sexual appetite and preoccupation, and high rates of sexual behavior) are more likely to have paraphilic interests or to be diagnosed with paraphilias (Kafka, 2009; Kafka \& Hennen, 2003; Långström \& Hanson, 2006).

Consistent with the notion that negative temperament may lead to a heightened risk of deviant interest and behavior (Agnew, 2002), experiencing negative emotions (e.g., frustration, rejection, ridicule, isolation, depression, and anger) was found to be an important factor associated with developing an interest in eight paraphilic activities (i.e., exhibitionism, scatologia, fetishism, urophilia, scatophilia, hebephilia, pedophilia, and zoophilia). As maladaptive corrective actions to cope with dysphoric feelings, paraphilic interests and subsequent paraphilic behavior may give an individual a strong sense of positive emotions (Yakeley \& Wood, 2014). Paraphilic interests and activities can be a form of retreat from unwanted emotions (e.g., anxiety and sadness), where behavioral habituation is possible (Hickey, 2002; Levine, Risen, \& Althof, 1990). In extreme situations, negative emotions may lead to the perpetration of delinquent and criminal behavior in the presence of paraphilic traits or diagnoses, such as biastophilia, hebephilia, and pedophilia. This is commonly observed in sexual offending behavior, such as violent sexual offenses and sexual homicides (Chan, 2020b; Chan, Beauregard, \& Myers, 2015a, b; Chan \& Beauregard, 2016). Of note, recognizing the shared risk factors (e.g., individual self-control and temperament) should not be overlooked as they have been consistently found to be significantly related to deviant interest and criminal behavior (DeLisi \& Vaughn, 2014).

This study also noted that social bonding was an important factor associated with seven paraphilic interests (i.e., voyeurism, scatologia, fetishism, frotteurism, sadism, biastophilia, and hebephilia). Put differently, individuals with weak social bonds were more likely to develope these atypical sexual interests. This finding generally supports Hirschi's (1969) theoretical proposition that the strength of social bonds is inversely related to the propensity to develop deviant interests and to engage in deviant and criminal behavior. Possessing strong social bonds with parents, family, prosocial peers, school, and society insulates an individual from developing deviant interests (e.g., paraphilic interest) and engaging in deviant activities. The impact of strong, prosocial bonds with parents and family members on an individual's psychological well-being and behavior 
is universal. Healthy and secure parental and familial attachment is essential to protect an individual from becoming involved in any deviant interests and activities (Chan \& Wong, 2019). Notwithstanding, Chan and Chui (2015) stressed that the roles that schools/universities (e.g., through a commitment to education) and society (e.g., through a belief in the criminal justice system) play in guarding an individual from developing deviant interests and engaging in deviant activities is equally important.

Several methodological limitations in this study require attention. One limitation of this study is its correlational nature. At most, the findings can only be interpreted in correlational terms. To better understand the causal relationships between the participants' psychosocial factors and their self-reported paraphilic interests, future research could adopt a longitudinal design and theoretical models that are more commonly used to comprehend sexual interests (e.g., the dual control model of sexual response; Bancroft \& Janssen, 2000; Granados, Carvalho, $\&$ Sierra, 2020). The dual control model broadly proposes that sexual responses involve an interaction between sexual excitatory and sexual inhibitory processes, in which individuals may vary in their propensity for both sexual excitation and sexual inhibition (Bancroft, Graham, Janssen, \& Sanders, 2009). Besides, future research could consider studying the relationship between sadistic interest and subsequent sadistic behavior, as it is regarded as the most severe paraphilia and is found to have linkages to sexual homicide (Chan, 2020a, b; Chan \& Beauregard, 2016; Chan et al., 2015a, b; DeLisi, Drury, Elbert, Tahja, Caropreso, \& Heinrichs, 2017). Another avenue for future research lies on the relationship between adverse childhood experiences and paraphilic interest and behavior. Past studies have noted a significant influence of the adverse childhood experiences on the development of paraphilic interest and behavior (Drury, Heinrichs, Elbert, Tahja, DeLisi, \& Caropreso, 2017; Leroux, Clow, Motayne, \& Seto, 2020). Second, this study was limited to self-reported data. Biases such as social desirability or retrospective recall bias may have influenced the participants' truthfulness in reporting their attitudes, perceptions, and experiences. Besides, some of the Western-developed measures adopted in this study have yet to be culturally validated. The validity of these measures used in an Asian population remains unclear. Hence, future studies could incorporate a measure for response bias to reduce participants' potential reporting biases and to use cultural-specific measures. Finally, recruiting participants from universities may prevent the reliable generalization of the findings to a wider Hong Kong population, including the young adult population. Future studies could recruit participants from all walks of life. Nevertheless, this sample could be considered representative of the wider Hong Kong university student population, as it was recruited from all universities in Hong Kong.

\section{Implications of the Findings}

The adverse outcomes of paraphilic interests, with potential escalation to paraphilic behavior, should not be understated. As stated by Carvalho (2018), paraphilic interests can escalate to becoming a motivational factor in some sexual offenses. These interests may range from a sexual preference for children, sadism, and nonconsenting coercive sex. The findings of this study have important implications for practice. Efforts to raise public awareness of healthy living (e.g., sexual health), especially among late adolescents and young adults, should be enhanced and begin much earlier in life. School- and community-based preventive efforts should incorporate education materials on the risks and outcomes associated with atypical sexual interest and behavior (e.g., paraphilic interest and behavior). Specific changes in risky sexual behavior, such as decreasing alcohol consumption and drug use before sex, transforming attitudes about safer and socially acceptable sexual practices (e.g., nonparaphilic activities), reducing the number of sexual partners, and negotiating condom use for safer sex, are essential educational messages to deliver to the younger population (Staton et al., 1999). Issues relevant to paraphilic interests and hypersexuality should also be addressed for young people to better understand the key effects of other aspects of sexuality, such as general sexual inhibition and excitation, on the development of paraphilic interests (Dawson et al., 2016). Government anti-drug campaigns should consider emphasizing the role of illicit drug (and alcohol) use in cultivating paraphilic interests.

In addition, school and community-based resources for positive and prosocial self-development and counseling services should be strengthened to encourage and assist those who need to promptly and efficiently cope with their negative emotions. Public seminars regarding psychological and emotional health should be conducted regularly to disseminate useful information regarding effective strategies for coping with negative emotions (e.g., anger management, self-assertiveness, and general positive emotions). Social norm interventions may be useful for individuals who are potentially at high risk of developing a paraphilic interest or who are presently engaging in paraphilic activities to address their misperceptions of alcohol consumption, paraphilic activities, and risky sexual behavior. This intervention not only can provide a remedial effect by reducing the frequency with which individuals who already engage in a behavior choose to do so (e.g., paraphilic behavior, risky behavior, and alcohol and drug use) but may also correct misperceptions among those who are not yet frequently engaging in such behavior (Martens, Page, Mowry, Damann, Taylor, \& Cimini, 2006). 
Funding This work was supported by the Strategic Research Grant (SRG) funded by City University of Hong Kong (CityU 7004958).

Open Access This article is licensed under a Creative Commons Attribution 4.0 International License, which permits use, sharing, adaptation, distribution and reproduction in any medium or format, as long as you give appropriate credit to the original author(s) and the source, provide a link to the Creative Commons licence, and indicate if changes were made. The images or other third party material in this article are included in the article's Creative Commons licence, unless indicated otherwise in a credit line to the material. If material is not included in the article's Creative Commons licence and your intended use is not permitted by statutory regulation or exceeds the permitted use, you will need to obtain permission directly from the copyright holder. To view a copy of this licence, visit http://creativecommons.org/licenses/by/4.0/.

\section{References}

Abramson, P. R., \& Imai-Marquez, J. (1982). The Japanese-American: A cross-cultural, cross-sectional study of sex guilt. Journal of Research in Personality, 16, 227-237.

Agnew, R. (1992). Foundation for a general strain theory of crime and delinquency. Criminology, 30(1), 47-87. https://doi.org/10. 1111/j.1745-9125.1992.tb01093.x

Agnew, R. (2002). Experienced, vicarious, and anticipated strain: An exploratory study on physical victimization and delinquency. Justice Quarterly, 19(4), 603-632. https://doi.org/10.1080/ 07418820200095371

Agnew, R., Brezina, T., Wright, J. P., \& Cullen, F. T. (2002). Strain, personality traits, and delinquency: Extending General Strain Theory. Criminology, 40(1), 43-72. https://doi.org/10. 1111/j.1745-9125.2002.tb00949.x

Ahlers, C. J., Schaefer, G. A., Mundt, I. A., Roll, S., Englert, H., Willich, S. N., \& Beier, K. M. (2011). How unusual are the contents of paraphilias? Paraphilia-associated sexual arousal patterns in a community-based sample of men. Journal of Sexual Medicine, 8(5), 1362-1370. https://doi.org/10.1111/j.1743-6109.2009.01597.x

Akers, R. L. (1985). Deviant behavior: A social learning approach. Belmont, CA: Wadsworth Publishing.

Akers, R. L. (1997). Criminological theories: Introduction and evaluation (2nd ed.). Los Angeles, CA: Roxbury.

Akers, R. L. (1998). Social learning and social structure: A general theory of crime and deviance. Boston, MA: Northeastern University Press.

American Psychiatric Association. (2013). Diagnostic and statistical manual of mental disorders (5th ed.). Washington, DC: American Psychiatric Publishing.

Arrigo, B. A., \& Purcell, C. E. (2001). Explaining paraphilias and lust murder: Toward an integrated model. International Journal of Offender Therapy and Comparative Criminology, 45(1), 6-31. https://doi.org/10.1177/0306624X01451002

Augustyn, M. B., \& McGloin, J. M. (2013). The risk of informal socializing with peers: Considering gender differences across predatory delinquency and substance use. Justice Quarterly, 30(1), 117-143. https://doi.org/10.1080/07418825.2011.597417

Ayonrinde, O., \& Bhugra, D. (2015). Paraphilias and culture. In D. Bhugra \& G. S. Malhi (Eds.), Troublesome disguises: Managing challenging disorders in psychiatry (2nd ed., pp. 199-217). West Sussex, UK: John Wiley \& Sons.

Baazeem, A. (2016). Challenges to practicing sexual medicine in the Middle East. Sexual Medicine Reviews, 4(3), 221-228. https:// doi.org/10.1016/j.sxmr.2016.04.001
Bancroft, J., \& Janssen, E. (2000). The dual control model of male sexual response: A theoretical approach to centrally mediated erectile dysfunction. Neuroscience \& Biobehavioral Reviews, 24(5), 571-579. https://doi.org/10.1016/S0149-7634(00)00024-5

Bancroft, J., Graham, C. A., Janssen, E., \& Sanders, S. A. (2009). The dual control model: Current status and future directions. The Journal of Sex Research, 46(2-3), 121-142. https://doi. org/10.1080/00224490902747222

Bandura, A. (1973). Aggression: A social learning analysis. Englewood Cliffs, NJ: Prentice Hall.

Bártová, K., Androvičová, R., Krejčová, L., Weiss, P., \& Klapilová, K. (2020). The prevalence of paraphilic interests in the Czech population: Preference, arousal the use of pornography, fantasy, and behavior. The Journal of Sex Research. Advance online publication. https://doi.org/10.1080/00224499.2019. 1707468

Baur, E., Forsman, M., Santtila, P., Johansson, A., Sandnabba, K., \& Långström, N. (2016). Paraphilic sexual interests and sexually coercive behavior: A population-based twin study. Archives of Sexual Behavior, 45, 1163-1172. https://doi.org/10.1007/s10508-015-0674-2

Behrendt, N., Buhl, N., \& Seidl, S. (2002). The lethal paraphiliac syndrome: Accidental autoerotic deaths in four women and a review of the literature. International Journal of Legal Medicine, 116(3), 148-152. https://doi.org/10.1007/s00414-001-0271-x

Bogaerts, S., Vanheule, S., Leeuw, F., \& Desmet, M. (2006). Recalled parental bonding and personality disorders in a sample of exhibitionists: A comparative study. The Journal of Forensic Psychiatry \& Psychology, 17(4), 636-646. https://doi.org/10.1080/ 14789940600915701

Bouchard, K. N., Dawson, S. J., \& Lalumière, M. L. (2017). The effects of sex drive and paraphilic interests on paraphilic behaviours in a nonclinical sample of men and women. The Canadian Journal of Human Sexuality, 26(2), 97-111. https://doi.org/10.3138/cjhs.262-a8

Bullough, V. L. (1976). Sexual variance in society and history. Chicago, IL: University of Chicago Press.

Burgess, A. W., Hartman, C. R., Ressler, R. K., Douglas, J. E., \& McCormack, A. (1986). Sexual homicide: A motivational model. Journal of Interpersonal Violence, 1(3), 251-272. https://doi.org/ $10.1177 / 088626086001003001$

Carnes, P. (1991). Gender differences in normal and sexually addicted populations. American Journal of Preventive Psychiatry \& Neurology, 3(1), Spring.

Carvalho, J. (2018). Paraphilic sexual interests and sexual offending: Implications for risk assessment and treatment. The Journal of Sexual Medicine, 15, 927-928. https://doi.org/10.1016/j.jsxm. 2018.02.002

Chan, H. C. O. (2015). Understanding sexual homicide offenders: An integrated approach. Basingstoke, UK: Palgrave Macmillan.

Chan, H. C. O. (2019a). A global casebook of sexual homicide. Singapore: Springer Nature.

Chan, H. C. O. (2019b). Exploring the overlap between victimization and offending among Hong Kong adolescents. Journal of Criminal Justice, 61, 72-80. https://doi.org/10.1016/j.jcrimjuc.2019.03.003

Chan, H. C. O. (2019c). Violent offending, nonviolent offending, and general delinquency: Exploring the criminogenic risk factors of Hong Kong male and female adolescents. International Journal of Offender Therapy and Comparative Criminology. Advance online publication. https://doi.org/10.1177/0306624X19881917

Chan, H. C. O. (2019d). Interpersonal and property victimization: An exploratory study of criminogenic risk factors of Hong Kong adolescents. Children and Youth Services Review, 106. Article, 104475, 1-9. https://doi.org/10.1016/j.childyouth.2019.104475

Chan, H. C. O. (2020a). The victim-offender overlap in sexual offending: Exploring a community-based sample of young adults in Hong Kong. Sexual Abuse: A Journal of Research and Treatment, 1-27. Advance online publication. https://doi.org/10.1177/1079063220981889 
Chan, H. C. O. (2020). Sexual sadism and psychopathy in sexual homicide. In A. Felthous \& H. Sass (Eds.), The Wiley International Handbook of Psychopathic Disorders and the Law (2nd ed., pp. 693-712). Hoboken, NJ: John Wiley \& Sons.

Chan, H. C. O., \& Beauregard, E. (2016). Nonhomicidal and homicidal sexual offenders: Prevalence of maladaptive personality traits and paraphilic behaviors. Journal of Interpersonal Violence, 31(13), 2259-2290. https://doi.org/10.1177/0886260515575606

Chan, H. C. O., \& Chui, W. H. (2012). Psychological correlates of violent and nonviolent Hong Kong juvenile probationers. Behavioral Sciences and the Law, 30(2), 103-120. https://doi.org/10. $1002 / \mathrm{bs} 1.2003$

Chan, H. C. O., \& Chui, W. H. (2013). Social bonds and school bullying: A study of Macanese male adolescents on bullying perpetration and peer victimization. Child \& Youth Care Forum, 42(6), 599-616. https://doi.org/10.1007/s10566-013-9221-2

Chan, H. C. O., \& Chui, W. H. (2015). Social bonds and self-reported nonviolent and violent delinquency: A study of traditional low risk, at-risk and adjudicated male Chinese adolescents. Child \& Youth Care Forum, 44(5), 711-730. https://doi.org/10.1007/ s10566-015-9303-4

Chan, H. C. O., \& Chui, W. H. (2017). The influence of low self-control on violent and nonviolent delinquencies: A study of male adolescents from two Chinese societies. Journal of Forensic Psychiatry and Psychology, 28(5), 599-619. https://doi.org/10.1080/14789949. 2015.1012534

Chan, H. C. O., \& Wong, D. S. W. (2019). Traditional school bullying and cyberbullying perpetration: Examining the psychosocial characteristics of Hong Kong male and female adolescents. Youth \& Society, 51(1), 3-29. https://doi.org/10.1177/0044118X16658053

Chan, H. C. O., Beauregard, E., \& Myers, W. C. (2015). Single-victim and serial sexual homicide offenders: Differences in crime, paraphilias, and personality traits. Criminal Behaviour and Mental Health, 25, 66-78. https://doi.org/10.1002/cbm.1925

Chan, H. C. O., Heide, K. M., \& Beauregard, E. (2011). What propels sexual murderers: A proposed integrated theory of social learning and routine activities theories. International Journal of Offender Therapy and Comparative Criminology, 55(2), 228250. https://doi.org/10.1177/0306624X10361317

Chan, H. C. O., Lo, T. W., Zhong, L. Y., \& Chui, W. H. (2015). Criminal recidivism of incarcerated male nonviolent offenders in Hong Kong. International Journal of Offender Therapy and Comparative Criminology, 59(2), 121-142. https://doi.org/10.1177/0306624X13502965

Chapple, C. L., McQuillan, J. A., \& Berdahl, T. A. (2005). Gender, social bonds, and delinquency: A comparison of boys' and girls' models. Social Science Research, 34(2), 357-383. https://doi. org/10.1016/j.ssresearch.2004.04.003

Cohen, L. E., \& Felson, M. (1979). Social change and crime rate trends: A routine activities approach. American Sociological Review, 44(4), 588-608. https://doi.org/10.2307/2094589

Critelli, J. W., \& Bivona, J. (2008). Women's erotic rape fantasies: An evaluation of theory and research. Journal of Sex Research, 45(1), 57-70. https://doi.org/10.1080/00224490701808191

Dang, S. S., Gorzalka, B. B., \& Brotto, L. A. (2019). Dual control model in a cross-cultural context: Role of sexual excitation in sexual response and behavior differences between Chinese and Euro-Caucasian women in Canada. Archives of Sexual Behavior, 48, 2519-2535. https://doi.org/10.1007/s10508-019-01535-7

Dawson, S. J., Bannerman, B. A., \& Lalumière, M. L. (2016). Paraphilic interests: An examination of sex differences in a nonclinical sample. Sexual Abuse: A Journal of Research and Treatment, 28(1), 20-45. https://doi.org/10.1177/1079063214525645

DeLisi, M., \& Vaughn, M. G. (2014). Foundation for a temperamentbased theory of antisocial behavior and criminal justice system involvement. Journal of Criminal Justice, 42(1), 10-25. https:// doi.org/10.1016/j.jcrimjus.2013.11.001
DeLisi, M., \& Wright, J. (2014). Social control theory of sexual homicide offending. In G. Bruinsma \& D. Weisburd (Eds.), Encyclopedia of criminology and criminal justice (pp. 4916-4922). New York: Springer.

DeLisi, M., Drury, A., Caropreso, D., Heinrichs, T., Tahja, K. N., \& Elbert, M. J. (2018). Antisocial personality disorder with or without antecedent conduct disorder: The differences are psychiatric and paraphilic. Criminal Justice and Behavior, 45(6), 902-917. https://doi.org/10.1177/0093854818765593

DeLisi, M., Drury, A., Elbert, M., Tahja, K., Caropreso, D., \& Heinrichs, T. (2017). Sexual sadism and criminal versatility: Does sexual sadism spillover into nonsexual crimes? Journal of Aggression, Conflict and Peace Research, 9(1), 2-12. https://doi.org/10.1108/ JACPR-05-2016-0229

Drury, A., Heinrichs, T., Elbert, M., Tahja, K., DeLisi, M., \& Caropreso, D. (2017). Adverse childhood experiences, paraphilias, and serious criminal violence among federal sex offenders. Journal of Criminal Psychology, 7(2), 105-119. https://doi.org/10.1108/ JCP-11-2016-0039

Espelage, D. L., Low, S., Rao, M. A., Hong, J. S., \& Little, T. D. (2014). Family violence, bullying, fighting, and substance use among adolescents: A longitudinal mediational model. Journal of Research on Adolescence, 24(2), 337-349. https://doi.org/10. 1111/jora. 12060

Felson, M., \& Cohen, L. (1980). Human ecology and crime: A routine activities approach.Human Ecology, 8, 389-406. https://doi.org/ 10.1007/BF01561001

Gottfredson, M. R. (2009). The empirical status of control theory in criminology. In F. T. Cullen, J. P. Wright, \& K. R. Blevins (Eds.), Taking stock: The status of criminological theory (Vol. 15, pp. 77-100). New Brunswick, NJ: Transaction Publishers.

Gottfredson, M. R., \& Hirschi, T. (1990). A general theory of crime. Standford, CA: Standford University Press.

Granados, R., Carvalho, J., \& Sierra, J. C. (2020). Preliminary evidence on how the dual control model predicts female sexual response to a bogus negative feedback. Psychological Reports. Advance online publication. https://doi.org/10.1177/0033294120907310

Grasmick, H. G., Tittle, C. R., Bursik, R. J., \& Arneklev, B. J. (1993). Testing the core implications of Gottfredson and Hirschi's general theory of crime. Journal of Research in Crime and Delinquency, 30(1), 5-29. https://doi.org/10.1177/0022427893030001002

Ha, O. K., \& Beauregard, E. (2016). Sex offending and low selfcontrol: An extension and test of the general theory of crime. Journal of Criminal Justice, 47, 62-73. https://doi.org/10.1016/j. jcrimjus.2016.07.005

Hanson, R. K., \& Morton-Bourgon, K. E. (2005). The characteristics of persistent sexual offenders: A meta-analysis of recidivism studies. Journal of Consulting and Clinical Psychology, 73(6), 1154-1163. https://doi.org/10.1037/0022-006X.73.6.1154

't Hart-Kerkhoffs, L. A., Vermeirenm, R. R. J. M., Jansen, L. M. C., \& Doreleijers, T. A. H. . (2011). Juvenile group sex offenders: A comparison of group leaders and followers. Journal of Interpersonal Violence, 26(1), 3-20. https://doi.org/10.1177/0886260510362882

Healey, J., \& Beauregard, E. (2016). Impulsivity as an etiological factor in sexual homicide. Journal of Criminal Justice, 48, 30-36. https://doi.org/10.1016/j.jcrimjus.2016.12.002

Hewitt, A., \& Beauregard, E. (2014). Sexual crime and place: The impact of the environmental context on sexual assault outcomes. Journal of Criminal Justice, 42, 375-383. https://doi.org/10. 1016/j.crimjus.2014.05.003

Hickey, E. (2002). Serial murderers and their victims (3rd ed.). Belmont, CA: Wadsworth.

Hirschi, T. (1969). Causes of delinquency. Berkeley, CA: University of California Press.

Hirschi, T., \& Gottfredson, M. (1994). The generality of deviance. New Brunswick, NJ: Transaction. 
Ho, C. C., Singam, P., Hong, G. E., \& Zainuddin, Z. M. (2011). Male sexual dysfunction in Asia. Asian Journal of Andrology, 13(4), 537-542. https://doi.org/10.1038/aja.2010.135

Joyal, C. C. (2014). How anomalous are paraphilic interests? Archives of Sexual Behavior, 43, 1241-1243. https://doi.org/ 10.1007/s10508-014-0325-z

Joyal, C. C., \& Carpentier, J. (2017). The prevalence of paraphilic interests and behaviors in the general population: A provincial survey. The Journal of Sex Research, 54(2), 161-171. https:// doi.org/10.1080/00224499.2016.11.39034

Joyal, C. C., Cossette, A., \& Lapierre, V. (2015). What exactly is an unusual sexual fantasy? Journal of Sexual Medicine, 12, 328-340. https://doi.org/10.1111/jsm.12734

Kafka, M. P. (1997). A monoamine hypothesis for the pathophysiology of paraphilic disorders. Archives of Sexual Behavior, 26, 343-358. https://doi.org/10.1023/A:1024535201089

Kafka, M. P. (2001). The paraphilia-related disorders: A proposal for a unified classificationof nonparaphilic hypersexuality disorders. Sexual Addiction \& Compulsivity, 8, 227-239. https:// doi.org/10.1080/107201601753459937

Kafka, M. P. (2009). Hypersexual disorder: A proposed diagnosis for DSM-V. Archives ofSexual Behavior, 39, 377-400. https://doi. org/10.1007/s10508-009-9574-7

Kafka, M. P., \& Hennen, J. (2002). A DSM-IV Axis I comorbidity study of males $(n=120)$ with paraphilias and paraphilia-related disorders. Sexual Abuse: A Journal of Research and Treatment, 14(4), 349-366. https://doi.org/10.1177/107906320201400405

Kafka, M. P., \& Hennen, J. (2003). Hypersexual desire in males: Are males with paraphilias different from males with paraphilia-related disorders? Sexual Abuse: A Journal of Research and Treatment, 15, 307-321. https://doi.org/10.1023/A:1025000227956

Kalra, G., Tandon, A., \& Rao, T. S. S. (2014). Sexual disorders in Asians: A review. Asian Journal of Psychiatry, 7, 80-82. https:// doi.org/10.1016/j.ajp.2013.11.010

Khar, B. (2008). Who's been sleeping in your head? The secret world of sexual fantasies. New York: Basic Books.

Lalumière, M. L., Harris, G. T., Quinsey, V. L., \& Rice, M. E. (2005). The causes of rape:Understanding individual differences in the male propensity for sexual aggression. Washington, DC: American Psychological Association.

Långström, N., \& Hanson, K. R. (2006). High rates of sexual behavior in the general population: Correlates and predictors. Archives of Sexual Behavior, 35, 37-52. https://doi.org/10.1007/ s10508-006-8993-y

Långström, N., \& Seto, M. C. (2006). Exhibitionistic and voyeuristic behavior in a Swedishnational population survey. Archives of Sexual Behavior, 35, 427-435. https://doi.org/10.1007/ s10508-006-9042-6

Laundra, K. H., Kiger, G., \& Bahr, S. J. (2002). A social development model of serious delinquency: Examining gender differences. Journal of Primary Prevention, 22(4), 389-407. https://doi.org/ 10.1023/A:1015279607215

Lee, S. C., Hanson, R. K., Calkins, C., \& Jeglic, E. (2020). Paraphilia and antisociality: Motivations for sexual offending may differ for American Whites and Blacks. Sexual Abuse: A Journal for Research and Treatment, 32(3), 335-365. https://doi.org/10. $1177 / 1079063219828779$

Leitenberg, H., \& Henning, K. (1995). Sexual fantasy. Psychological Bulletin, 117(3), 469-496. https://doi.org/10.1037/0033-2909. 117.3.469

Leroux, E. J., Clow, K., Motayne, G., \& Seto, M. C. (2020). The association of childhood sexual abuse with non-paraphilic and paraphilic sexual behaviors among adolescents who have sexually offended. The Journal of Sex Research, 57(9), 1189-1201. https://doi.org/10.1080/00224499.2020.1749821
Levine, S. B., Risen, C. B., \& Althof, S. E. (1990). Essay on the diagnosis and nature of paraphilia. Journal of Sex \& Marital Therapy, 16, 89-102.

Love, S. R. (2006). Illicit sexual behavior: A test of self-control theory. Deviant Behavior, 27, 505-536. https://doi.org/10.1080/ 01639620600781464

Marsh, P. J., Odlaug, B. L., Thomarios, N., Davis, A. A., Buchanan, S. N., Meyer, C. S., \& Grant, J. E. (2010). Paraphilias in adult psychiatric inpatients. Annals of Clinical Psychiatry, 22(2), 129-134.

Marshall, W. L. (2007). Diagnostic issues, multiple paraphilias, and comorbid disorders in sexual offenders: Their incidence and treatment. Aggression and Violent Behavior, 12, 16-35. https:// doi.org/10.1016/j.avb.2006.03.001

Martens, M. P., Page, J. C., Mowry, E. S., Damann, K. M., Taylor, K. K., \& Cimini, M. D. (2006). Differences between actual and perceived student norms: An examination of alcohol use, drug use, and sexual behavior. Journaof American College Health, 54(5), 295-300. https://doi.org/10.3200/JACH.54.5.295-300

Messerschmidt, J. W. (1993). Masculinities and crime: Critique and reconceptualization of theory. Lanham, MD: Rowman and Littlefield.

Meston, C. M., Trapnell, P. D., \& Gorzalka, B. B. (1996). Ethnic and gender differences in sexuality: Variations in sexual behavior between Asian and non-Asian university students. Archives of Sexual Behavior, 25(1), 33-72. https://doi.org/10.1007/BF02437906

Mills, L. G. (2003). Insult to injury: Rethinking our responses to intimate abuse. Princeton, NJ: Princeton University Press.

Mundy, C. L., \& Cioe, J. D. (2019). Exploring the relationship between paraphilic interests, sex, and sexual and life satisfaction in nonclinical samples. The Canadian Journal of Human Sexuality, 28(3), 304-316. https://doi.org/10.3138/cjhs.2018-0041

Muraven, M., Pogarsky, G., \& Shmueli, D. (2006). Self-control depletion and the general theory of crime. Journal of Quantitative Criminology, 22(3), 263-277. https://doi.org/10.1007/ s10940-006-9011-1

Nunnally, J. (1978). Psychometric theory. New York: McGraw-Hill. Osgood, D. W., Wilson, J. K., O’Malley, P. M., Bachman, J. G., \& Johnston, L. D. (1996). Routine activities and individual deviant behavior. American Sociological Review, 61(4), 635655. https://doi.org/10.2307/2096397

Osgood, D. W., Wilson, J. K., O’Malley, P. M., Bachman, J. G., \& Johnston, L. D. (1996). Routine activities and individual deviant behavior. American Sociological Review, 61(4), 635-655. https://doi.org/10. 2307/2096397

Posick, C. (2013). The overlap between offending and victimization among adolescents: Results from the second International SelfReport Delinquency Study. Journal of Contemporary Criminal Justice, 29(1), 106-124. https://doi.org/10.1177/1043986212471250

Reiss, I. L. (1986). Journey into sexuality: An exploratory voyage. Englewood Cliffs, NJ: Prentice Hill.

Sacarellos, C. D., Wright, J. P., Almosaed, N. F., Moghrabi, S. S., Bashatah, F. S., \& Morgan, M. A. (2016). Crime in the Kingdom: The effects of low self-control in a Saudi Arabian sample of youth. Youth Violence and Juvenile Justice, 14(3), 291-312. https://doi.org/10.1177/1541204015616663

Schreck, C. J., Fisher, B. S., \& Miller, J. M. (2004). The social context of violent victimization: A study of delinquent peer effect. Justice Quarterly, 21(1), 23-48. https://doi.org/10.1080/07418820400095731

Seto, M. C., Lalumière, M. L., Harris, G. T., \& Chivers, M. L. (2012). The sexual responses of sexual sadists. Journal of Abnormal Psychology, 121(3), 739-753. https://doi.org/10.1037/a0028714

Sijtsma, K. (2009). On the use, the misuse, and the very limited usefulness of Cronbach's alpha. Psychometrika, 74(1), 107-120. https://doi.org/10.1007/s11336-008-9101-0 
Staton, M., Leukefeld, C., Logan, T., Zimmerman, R., Lynam, D., Milich, R., et al. (1999). Risky sex behaviour and substance use among young adults. Health \& Social Work, 24(2), 147-154. https://doi.org/10.1093/hsw/24.2.147

Straus, M. A., \& Kantor, G. K. (2005). Definition and measurement of neglectful behavior: Some principles and guidelines. Child Abuse \& Neglect, 29, 19-29. https://doi.org/10.1016/j.chiabu. 2004.08.005

Sutherland, E. H. (1947). Principles of criminology (4th ed.). Philadelphia, PA: Lippincott.

Tamatea, A. J., Webb, M., \& Boer, D. P. (2011). The role of culture in sexual offender rehabilitation: A New Zealand perspective. In D. P. Boer, R. Eher, L. A. Craig, M. H. Miner, \& F. Pfäfflin (Eds.), International perspectives on the assessment and treatment of sexual offenders: Theory, practice, and research (pp. 313-330). Chichester, UK: Wiley-Blackwell.

Tillyer, M. S., \& Wright, E. M. (2014). Intimate partner violence and the victim-offender overlap. Journal of Research in Crime and Delinquency, 51(1), 29-55. https://doi.org/10.1177/0022427813484315

Turchik, J. A., \& Garske, J. P. (2009). Measurement of sexual risk taking among college students. Archives of Sexual Behavior, 38, 936-948. https://doi.org/10.1007/s10508-008-9388-z

Warr, M. (2002). Companions in crime: The social aspects of criminal conduct. Cambridge, MA: Cambridge University Press.
Williams, K. M., Cooper, B. S., Howell, T. M., Yuille, J. C., \& Paulhus, D. L. (2009). Inferring sexually deviant behavior from corresponding fantasies: The role of personality and pornography consumption. Criminal Justice and Behavior, 36(2), 198-222. https://doi.org/10.1177/0093854808327277

Winder, B., Fedoroff, J. O., Grubin, D., Klapilová, K., Kamenskov, M., Tucker, D., et al. (2019). The pharmacologic treatment of problematic sexual interests, paraphilic disorders, and sexual preoccupation in adult men who have committed a sexual offence. International Review of Psychiatry, 31(2), 159-168. https://doi. org/10.1080/09540261.2019.1577223

World Health Organization (2010). International statistical classification of diseases and related health problems (10th rev.). Retrieved 14 May 2020 from https://icd.who.int/browse10/2010/en

Yakeley, J., \& Wood, H. (2014). Paraphilias and paraphilic disorders: Diagnosis, assessment and management. Advances in psychiatric treatment, 20(3), 202-213.

Yoon, I. S., Houang, S. T., Hirshfield, S., \& Downing, M. J. (2016). Compulsive sexual behavior and HIV/STI risk: A review of current literature. Current Addiction Reports, 3, 387-399. https:// doi.org/10.1007/s40429-016-0121-z

Publisher's Note Springer Nature remains neutral with regard to jurisdictional claims in published maps and institutional affiliations. 